\title{
Elevated CA19-9
}

National Cancer Institute

\section{Source}

National Cancer Institute. Elevated CA19-9. NCI Thesaurus. Code C138070.

A laboratory test result indicating the presence of an increased level of the tumorassociated antigen (TAA) CA19-9 in a biological sample. 